\title{
Effects of steviol on cytotoxicity, adipogenesis, ROS concentration and gene expression in 3T3-L1 Cell Line
}

\author{
$\underline{\text { Jakub Kurek }}^{1}$, Joanna Zielińska-Wasielica ${ }^{2}$, Katarzyna Kowalska ${ }^{2}$, Anna Olejnik ${ }^{2}$ and \\ Zbigniew Krejpcio ${ }^{1}$ \\ ${ }^{1}$ Institute of Human Nutrition and Dietetics, Poznańn University of Life Sciences, Poznań, Poland, Poznań, Poland and \\ ${ }^{2}$ Department of Biotechnology and Food Microbiology, Poznan University of Life Sciences, Poznań, Poland, \\ Poznań, Poland
}

\section{Abstract}

The increasing prevalence of diabetes mellitus has become one of the world's most serious public health problems. This reflects an increase in associated risk factors such as being overweight or obese. Currently available therapies are associated with a number of adverse effects, so there is a need to search for new substances that can support the treatment.

Stevia rebaudiana Bertoni is a plant famous for its sweetness due to the content of steviol glycosides that are derivatives of diterpene - steviol. Stevia and its glycosides are becoming popular in the world of science due to their anti-diabetic potential. However, the mechanisms responsible for its action are not fully understood and require further investigation.

The aim of this study was to evaluate the effects of steviol on adipogenesis, intracellular ROS generation and the gene expression, as well as cytotoxicity in murine 3T3-L1 cell line. Cell viability, adipocyte differentiation, intracellular ROS generation and the influence on gene expression in the presence of steviol (in concentrations of 1-100 $\mu \mathrm{M}$ ) was determined using MTT assay, Oil Red O staining, NBT methods and RT-PCR. It was found that steviol in concentrations up to $100 \mu \mathrm{M}$ did not affect proliferation of cells. Also, there were no effects on lipid accumulation and intracellular ROS generation with examined concentrations $(0-100 \mu \mathrm{M})$. The agent reduced the expression of genes regulating adipogenesis and lipogenesis processes: PPAR $\gamma$ (at concentrations of 10 and $100 \mu \mathrm{M}$, by 38.1 and $45.3 \%$ ), $\mathrm{C} / \mathrm{EBP} \alpha$ (at concentrations of 1,10 and $100 \mu \mathrm{M}$, by 36.9, 61.9 and $45.3 \%$ ), SREBP-1 (at concentrations of 10 and $100 \mu \mathrm{M}$, by 49.8 and $37.2 \%$ ), LPL (at concentrations of 1,10 and $100 \mu \mathrm{M}$, by $45,33.7,30.8 \%$ ), aP2 (at concentrations of 1,10 and $100 \mu \mathrm{M}$, by 36.9 , 23.8, 52.4\%), FAS (at concentrations of 1,10 and $100 \mu \mathrm{M}$, by 55.4, 22.4, 55.6\%), LEP (at concentrations of 1,10 and $100 \mu \mathrm{M}$, by 27.5 , $59.2,68.6 \%$ ), ADIPQ (at concentration of $100 \mu \mathrm{M}$, by $55.6 \%$ ) and RSTN (at concentrations of 1,10 and $100 \mu \mathrm{M}$, by $36.9,61.9,63.9 \%$ ). Steviol lowered the expression of gene coding glucose transporter GLUT4 (at concentrations of 10 and $100 \mu \mathrm{M}$, by 33.7 and $37.2 \%$ ).

The results of this study seem to confirm that the mechanisms of anti-diabetic effects of steviol may be related to inhibition of expression of genes responsible for adipogenesis, lipogenesis and glucose transport in cells.

The presented work is an integral part of the research project

(National Science Centre, Poland, NCN 2017/27/B/NZ29/00677)

\section{Conflict of Interest}

There is no conflict of interest 